\title{
Memória cotidiana e comunicação
}

Fernando Barone

Professor Doutor da Escola Superior de Educadores

de Infância Maria Ulrich.

E-mail: fbarone@netcabo.pt

Este trabalho constitui um estudo interdisciplinar sobre a memória social na perspectiva de uma Teoria da Memória Social. Busca investigar e compreender os tipos ideais de memória cotidiana inspirando-se, metodologicamente, no conceito de tipo ideal weberiano. Desenvolve a idéia de que a Sociologia, desde Maurice Halbwachs ${ }^{1}$, afastou-se de um conceito de memória possivel/temporalidade possivel, proposto no interior da Filosofia por autores como Nietzsche, Husserl e Bergson, para reforçar uma representação da memória social adaptada à temporalidade contida nos processos culturais da modernidade e na sua lógica produtiva.

Destaca-se aqui nosso interesse pelo que chamamos de modos de memória, que pode ser definido, em um primeiro momento, como o conjunto de características fundadoras do comportamento cotidiano que está associado à temporalidade social; modos de viver o tempo; características da velocidade sociocorporal no contexto da coletividade; determinação da finalidade e vivências dos ritmos socioculturais; práticas e representações das finalidades técnicas ou vitais, práticas e representações das funções sociais. Essa perspectiva, que queremos fixar e desenvolver neste trabalho, toma a memória não apenas como o instrumental cognitivo do sujeito, para representar e classificar o mundo, mas compreende, sobretudo, o conjunto de elementos sociocorporais construídos e disseminados em sociedade - fatores de reprodução e transformação social.

Apresenta-se como conjunto de referências teóricas deste trabalho a aproximação à fenomenologia da memória no cotidiano, presente nas obras de Paul Ricoeur, Gilles Deleuze, Pierre Bourdieu, Paul Connerton e autores ligados à Escola de Palo Alto. Este conjunto constitui a base teórica de referência para além de autores clássicos e modernos, tais como Henri Bergson ${ }^{2}$ do qual se tomaram os conceitos fundamentais que deram origem ao modelo de análise.

O modelo de análise desenvolvido, objetivo principal deste trabalho, baseia-se na revisão do chamado dualismo bergsoniano refletido nos conceitos de espírito e matéria, bem como nas outras dualidades daí derivadas, tais como o conceito de duração - opondo-se a uma noção de abstração - e também ao par da oposição memória-hábito e memória-lembrança, entre outros.

A educação e a escola, como fatores de socialização indispensáveis, encontram-se vinculadas aos modos de comunicação e memória na nossa sociedade,

\footnotetext{
1. HALBWACHS, Maurice. A memória coletiva. São Paulo: Vértice, 1990.

2. BERGSON, Henri. Matiere et mémoire; essai sur la relation du corps a l'esprit. (Matéria e memória; ensaio sobre a relação do corpo do espírito). Genève: Éditions Albert Skira, 1946. 259 p.; O pensamento e o movente (Introdução). In:__. Bergson: cartas, conferências e outros escritos. São
} 
exercendo, de forma complexa, contraditória e coincidente, duas tendências de viver a temporalidade no dia-a-dia. A primeira, voltada para a adaptação ao mundo: objetividade, simplicidade, reprodução, ação, ciência, inteligência e as características temporais abstratas - linearidade, separação e fragmentação do mundo. A segunda, dirigida à reflexão e, particularmente, à reflexão referenciada ao tempo vivido e a viver: subjetividade, complexidade, transformação, reflexão, conhecimento, intuição e as características da temporalidade durável - unidade, continuidade e simultaneidade.

A partir dessas referências teóricas, elaborou-se um instrumental de análise que associa as características da dualidade duração/abstração aos elementos: o tempo, o si mesmo, o outro e a comunicação, determinando indicadores que investigam e classificam um corpus de análise constituído por discursos de professores do primeiro ciclo do Ensino Básico obtidos por meio de entrevistas semidirigidas. A aplicação do instrumental de análise ao corpus permitiu aferir a pertinência do modelo e a viabilidade do seu desenvolvimento. No presente texto apresentaremos, de modo resumido, a estrutura do modelo de análise e o instrumento de observação adaptado para a coleta de dados no universo educativo, no caso específico, os dados referentes às práticas memoriais de docentes do primeiro ciclo.

\section{FUNDAMENTOS TEÓRICOS}

O conceito de memória social se impôs às Ciências Sociais principalmente a partir dos estudos de Maurice Halbwachs (1990) que, no início do século $\mathrm{XX}$, analisou, de forma pioneira, os fenômenos relacionados com a memória coletiva propondo o estudo científico dos processos sociais que determinam a memória dos grupos e da sociedade. Até então, este objeto, sob o nome de memória apenas, era explorado pela Psicologia e pela Psicanálise nascente e apresentava uma abordagem do tema marcada, basicamente, pela natureza individual atribuída à memória humana.

Tanto a Psicologia como a Sociologia exibiam, a esta altura, as marcas positivistas que mais fortemente as caracterizaram no início. Ao mesmo tempo, no plano do pensamento filosófico, o sentido atribuído à memória mantinha uma característica menos instrumental e mais preocupada com a possível memória humana. Estamos nos referindo aqui a autores como Nietzsche, Husserl e Bergson que, preocupados com o tema do tempo e da memória no mundo contemporâneo, tentam alertar para os problemas relacionados com as ciências positivas e a sua servidão em face do crescimento da industrialização e da lógica produtivista, inibidores da consciência e da reflexão não-instrumental.

Bergson (1946), supondo que o homem se afastava cada vez mais de uma vivência temporal integrada e aberta à consciência, propôs os conceitos de memória-hábito e memória-lembrança que se alinhavam, respectivamente, à oposi-

Paulo: Abril Cultural, 1979 p. 99-151; Ensaio sobre os dados imediatos da consciência. Lisboa: Edições 70, 1988. ção matéria e espirito. Bergson denominou memória-hábito a resposta automática determinada pelo hábito social com seu desempenho repetido de performances mentais e corporais que envolvem atividades cotidianas, tais como nadar, andar de bicicleta e responder automaticamente a múltiplas solicitações do meio. 
Em oposição à memória-hábito, concebeu a noção de memória-lembrança, ou memória verdadeira, que atribui à memória humana a capacidade de suplantar as determinações do hábito, constituindo-se em fator de consciência e liberdade do sujeito ante o meio e a cultura envolventes. A este conceito estariam associadas as características temporais simultaneidade, unidade e continuidade exercitadas acerca, e a partir, da realidade tangível e opostas às da memória-hábito.

Nessa perspectiva, a filosofia bergsoniana associará os pares de oposição, derivados do par matéria e espírito-memória, aos seguintes pares de oposição: abstração-manipulação técnica $x$ duração-consciência, memória-hábito x memória-lembrança, ciência x filosofia, ação x conhecimento, inteligência x intuição, adaptação x experimentação, seleção $x$ atenção, além dos pares já citados: unidade $x$ separação, continuidade $x$ fragmentação, linearidade $x$ simultaneidade.

Em resumo, o pensamento de Bergson não abre mão de um raciocínio que recusa tomar da realidade apenas a sua materialidade objetivável. Ao contrário, pleiteia a contínua participação da consciência e do espírito que criam essa mesma materialidade.

Apesar da intervenção histórica de Bergson, e de outros filósofos nãoracionalistas, ao longo do século XX o desenvolvimento dos estudos sobre a memória, e particularmente sobre a memória social, tenderam à manutenção da orientação científica em detrimento da filosófica. Isso significa dizer que tanto a Psicologia como a Sociologia, desde Halbwachs, ao investigarem a memória em sociedade, mantiveram, em essência, uma perspectiva calcada nos objetos mais explícitos do real sem considerar as dimensões do possível, ou daquilo que se preserva na sombra das práticas sociais. Nesse sentido, Connerton ${ }^{3}$ entende que o objeto memória foi colonizado por disciplinas úteis aos sistemas sociais dominantes, tais como a Psicanálise, que explorou a memória pessoal ou memória de si, e a Psicologia Experimental, que pesquisou a memória cognitiva ou memória dos objetos e do mundo. Estas teorias relegaram ao esquecimento a memóriahábito ou memória corporal e automática, responsável pela incorporação dos gestos sociais e da linguagem, adquiridos nos processos de socialização.

\section{ORDENS DO TEMPO E OPOSIÇÕES SOCIOTEMPORAIS}

O par de oposição com o qual trabalhamos pode ser apresentado de forma geral a partir da síntese de Pomiam $^{4}$, segundo a qual a nossa sociedade está marcada por duas grandes ordens do tempo. De um lado, aquela que concebe o tempo criado para a organização e a produção, identificado com a ciência: tempo físico, quantitativo, abstrato, homogêneo, cenário anódino da organização produtiva. Por outro lado, registra-se o tempo orgânico dos humores do corpo, dos acontecimentos cíclicos da natureza, das marcas do envelhecimento, do tempo psicológico, dos traços individuais que sobrevivem aos indivíduos e se reproduzem de uma geração a outra. Enfim, tempo qualitativo da duração, da subjetividade, da exteriorização de qualidades interiores. Para Pomiam, esta realidade confirma a hipótese de Bergson, na fase adulta do seu pensamento,
3. CONNERTON, Paul. Como as sociedades recordam. Oeiras: Celta, 1993. 126p.

4. POMIAN, Krzysztof. L'ordre du temps (A ordem do tempo). Paris: Gallimard, 1984. p. 313. 
ao demonstrar que o tempo abstrato constituía simples justaposição instantânea no espaço, enquanto o tempo durável era continuidade de interpenetração no tempo.

Ao longo do nosso trabalho de investigação bibliográfica, confirmamos o reaparecimento constante das oposições que dão conta da nossa dualidade fundamental: abstração (tempo social abstrato) e duração (tempo social durável).

QUADRO DE CONCEITOS OPOSTOS/COMPLEMENTARES

ASSOCIADOS À MEMÓRIA

\begin{tabular}{|c|c|c|}
\hline Matéria & Espírito & \multirow[t]{10}{*}{ Bergson } \\
\hline Abstração/Manipulação técnica* & Duração/Reflexão com vista a fins & \\
\hline Ciência & Filosofia & \\
\hline Ação & Conhecimento & \\
\hline Inteligência & Intuição & \\
\hline Separação & Unidade & \\
\hline Fragmentação & Continuidade & \\
\hline Linearidade & Simultaneidade & \\
\hline Adaptação & Experimentação & \\
\hline Seleção & Atenção & \\
\hline $\begin{array}{l}\text { Vergangenheit: o passado é } \\
\text { aquilo que já não é mais }\end{array}$ & $\begin{array}{l}\text { Gewesenheit: o passado é aquilo } \\
\text { que já foi e ainda é }\end{array}$ & Heidegger \\
\hline Memória & Esquecimento & \multirow[t]{3}{*}{ Nietzsche } \\
\hline Valor Moral/Racionalidade & Instinto & \\
\hline História & Eterno retorno & \\
\hline Representação & Recordação & \multirow[t]{3}{*}{ Freud } \\
\hline Melancolia & Luto & \\
\hline Inconsciente & Consciente & \\
\hline História x Memória & Consciência histórica & \multirow[t]{4}{*}{ Ricoeur } \\
\hline Si mesmo & Si mesmo como outro & \\
\hline Representação & Interpretação & \\
\hline História & Memória & \\
\hline Recognição/Representação & Repetição/Circularidade & \multirow[t]{2}{*}{ Deleuze } \\
\hline \multicolumn{2}{|c|}{ Repetição e eterno retorno } & \\
\hline Reprodução do habitus & Transformação do habitus & Bourdieu \\
\hline Hábito & Linguagem & \multirow[t]{2}{*}{ Connerton } \\
\hline Incorporação & Inscrição & \\
\hline Ordem & Desordem & \multirow[t]{2}{*}{ Morin } \\
\hline \multicolumn{2}{|c|}{ Identificação Ordem/Desordem } & \\
\hline Vida heróica & Vida cotidiana & Featherston \\
\hline
\end{tabular}

5. CLEMENT, E. et al. Dicionário prático de Filosofia. Lisboa: Terramar, 1999. 407p.

* Aqui, o conceito de abstração é tratado como fator de contraposição ao conceito de duração. Bergson não utiliza diretamente este termo. Clement ${ }^{5}$, ao condensar o conceito de duração em Bergson, utiliza o termo instante para designar o termo oposto. A duração seria assim o fundamento do próprio do ser, que o tempo físico - tempo abstrato - é incapaz de agarrar, na medida em que é apenas a transposição simbólica do tempo no espaço. Também em Clement: "A duração é assim o tempo concreto, não abstrato, o tempo qualitativo, não quantitativo, o tempo heterogêneo, não homogêneo, contrariamente ao tempo medido e calculado dos físicos". 
Quando assumimos esse conjunto de dualidades como fator de construção do nosso modelo de análise, assumimos também a hipótese de que essas duas forças antagônicas da temporalidade organizavam-se, no cotidiano, complexa e contraditoriamente, caracterizando os diferentes meios sociais a partir dos modos distintos de entender o tempo e vivê-lo, também, enquanto passado. Dessa forma, demos os primeiros passos para observar a realidade desde uma perspectiva memório-temporal, enfatizando as diferentes maneiras e hábitos de viver e interpretar o tempo e o passado.

\section{UM MODELO DE ANÁLISE PARA A MEMÓRIA COTIDIANA}

A partir dos elementos teóricos básicos apresentados, concebemos um modelo de análise inspirado, em seus fundamentos, no par de oposição memórialembrança/duração x memória-hábito/abstração.

Uma forma possível de organizar um quadro teórico, que contemple a prática da memória no cotidiano, será aquela que apresente os seguintes conceitos constituintes da duração: unidade, continuidade e simultaneidade; e da abstração: separação, fragmentação e linearidade. Esta elaboração do quadro teórico preocupase em resgatar a memória-lembrança a partir de uma fenomenologia da memória e de sua importância para a construção da temporalidade e do mundo.

A partir do pensamento de Bergson e do conceito de duração: unidade ou indivisibilidade; continuidade, simultaneidade ou mudança, propomos um conjunto conceitual capaz de descrever tendências de ação da memória cotidiana.

Essas categorias evocam formas e práticas de comportamento diante do mundo e da temporalidade e referem-se ao conceito duplo de duração/abstração, conceitos que, no plano fenomenológico, não existem na sua forma pura. De outro modo, podemos dizer que os modos de memória variam a partir do jogo de equilíbrio e interação entre a duração/abstração; a memória-lembrança e a memória- hábito ou, de modo geral, entre matéria e espírito. Designamos tais elementos como dimensões e nos propomos a pensá-las como base de um modelo de análise em construção.

O conceito de dimensão é aqui utilizado no sentido de abarcar as características fundamentais das práticas temporais e de memória expressas no cotidiano. Acrescenta-se que estas práticas operam a consolidação de hábitos de memória no dia-a-dia das práticas sociais, com especial atenção para as práticas de educação formal.

São três as categorias constitutivas do hábito da memória cotidiana: a unidade, a continuidade e a simultaneidade. Estes conceitos, por seu turno, refletem seus contrários complementares: a separação, a fragmentação e a linearidade.

Os conceitos de si mesmo, outro e comunicação surgem para nós como temas do sujeito/objeto no mundo e seguem o plano do processo de comunicação como realidade de interação comunicativa, de acordo com o Interacionismo Simbólico, implícito na Escola de Palo Alto. 
Tomamos as características gerais do tempo organizadas sob os conceitos opostos tempo concreto/tempo abstrato e os relacionamos com os conceitos de si mesmo, outro, comunicação e tempo, obtendo assim um novo conjunto composto de doze categorias resultantes do cruzamento entre as características temporais e o plano do sujeito/objeto: unidade/separação do si mesmo; unidade/separação do outro; unidade/separação da comunicação e assim por diante. No quadro a seguir, representamos graficamente o modelo de análise na sua estrutura básica.

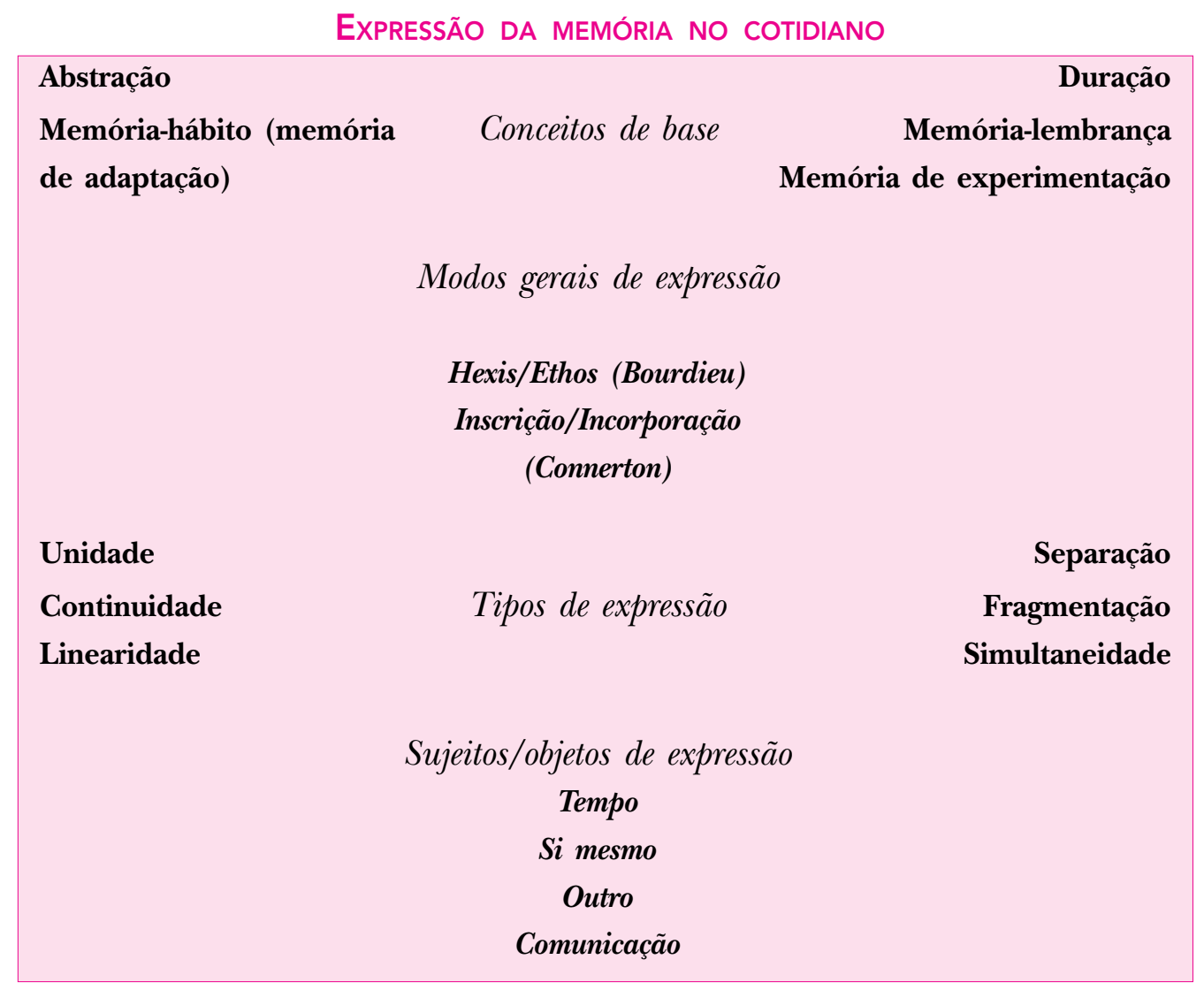

Com relação ao conceito de hexis e ethos, neste quadro procuramos caracterizar genericamente aquilo que Bourdieu' chama o habitus: "Um sistema de disposições duráveis adquiridas por um indivíduo no decorrer do processo de socialização". O habitus manifesta-se através do que o autor denomina esquemas (schèmes) ou os modos de percepção e ação interiorizadas pelo indivíduo ao longo do seu percurso espaço-tempo.

Para nós, tanto a memória-lembrança como a memória-hábito manifestam-se poder simbólico. Rio de Janeiro: Difel, 1989; Raisons pratiques: sur la théorie de l' action (Razões práticas: sobre a teoria da ação). Paris: Éditions de Seuil, 1994.

7. CONNERTON, Paul. Como as sociedades recordam. Oeiras: Celta, 1993. $126 \mathrm{p}$. como hábito, seja sob a forma de hexis, seja sob a forma de ethos. O ethos designa os princípios ou valores sob a forma de práticas, formas íntimas e não conscientes dos comportamentos morais que regem a conduta cotidiana: a forma interiorizada, não-consciente da moral. A hexis corporal corresponde às posturas, disposições do corpo interiorizadas inconscientemente pelo indivíduo ao longo do seu percurso no tempo/espaço. Acrescentamos, neste plano dos modos gerais de expressão, os conceitos de inscrição e incorporação, presentes em Connerton ${ }^{7}$. 
Inscrição corresponde, nas sociedades modernas, à predominância dos mecanismos de registro das mensagens e saberes, enquanto, por oposição, incorporação constitui a memória habitual sedimentada no corpo.

Tanto o ethos quanto a hexis referem-se a um processo inconsciente, ou automático, de agir no mundo. Revela inteligência adaptativa e a combinação de práticas já incorporadas pelo indivíduo.

Quadro do Modelo de Análise

\begin{tabular}{|c|c|}
\hline Duração & Abstração \\
\hline Memória-lembrança & Memória-hábito \\
\hline Unidade & Separação \\
\hline Continuidade & Fragmentação \\
\hline Simultaneidade & Linearidade \\
\hline \multicolumn{2}{|c|}{ Do tempo } \\
\hline \multicolumn{2}{|c|}{ De si } \\
\hline \multicolumn{2}{|c|}{ Do outro/do mundo (do espaço) } \\
\hline \multicolumn{2}{|c|}{ Da comunicação (relação/interação) } \\
\hline UNIDADE & SEPARAÇÃO \\
\hline Do tempo & Do tempo \\
\hline De si & De si \\
\hline Do outro/do mundo (atenção) & Do outro/do mundo (seleção) \\
\hline Da comunicação & Da comunicação \\
\hline CONTINUIDADE & FRAGMENTAÇÃO \\
\hline Do tempo & Do tempo \\
\hline De si (temporalidade alargada de si) & De si (temporalidade fragmentada de si) \\
\hline Do outro / do mundo & Do outro/do mundo \\
\hline Da comunicação & Da comunicação \\
\hline SIMULTANEIDADE & LINEARIDADE \\
\hline Do tempo & Do tempo \\
\hline De si & De si \\
\hline Do outro/do mundo & Do outro/do mundo \\
\hline Da comunicação & Da comunicação \\
\hline
\end{tabular}

\section{O INSTRUMENTAL DE ANÁLISE PROJETADO NO CAMPO DAS PRÁTICAS EDUCATIVAS}

O modelo apresentado acima permite a projeção empírica de seus conceitos no plano da educação. A questão básica que permite esta projeção pode ser assim resumida: como o professor transmite, reforça ou põe em causa hábitos de memória e de vivência social do tempo nas nossas sociedades?

A estrutura do modelo permite a organização de indicadores qualitativos relacionados diretamente aos traços empíricos destacados nos discursos. Tais indicadores estão intrinsecamente ligados entre si, embora esta divisão os des- 
taque à maneira de indicadores mais associados a esta ou aquela característica genérica dos tempos durável/abstrato em fusão e/ou contradição. Dentro de cada dimensão da duração/abstração (unidade/continuidade/simultaneidade), apresentam-se os enunciados indicadores subordinados às categorias dos objetos destacados (tempo/si mesmo/outro/comunicação). Passamos a discriminar, no interior de cada conceito derivado, os seus indicadores correspondentes.

\section{DIMENSÃO UNIDADE/SEPARAÇÃO}

\section{Unidade/separação do tempo}

Enuncia divisão utilitária do tempo em geral: o professor apresenta (ou não) preocupação (intenção de pensamento e trabalho) - aqui, com o sentido mais associado à idéia de pré-ocupação ${ }^{8}$, ou seja, intenção prévia de pensamento e trabalho em face de determinada atividade. Pré-ocupação, substantivo feminino - ocupação prévia -, com os modelos temporais montados sobre rotinas de ação.

Enuncia tempo de unidade: o professor apresenta (ou não) preocupação com o tempo que se contrapõe ao tempo das rotinas cristalizadas. O professor apresenta (ou não) preocupação com a separação do tempo (e das atividades) em blocos isolados e sem ligação.

Enuncia centralidade do sujeito (aluno/professor) como construtor do tempo: o professor apresenta (ou não) o sujeito como centro do processo de duração/ abstração. Nesse caso, o professor enuncia a idéia de preparar (ou não) o aluno e a si mesmo para exercer a expansão do presente (tempo de unidade).

Enuncia pensamento/prática de equilíbrio entre os tempos: o professor apresenta (ou não) preocupação em expandir a vivência do presente como duração, ao mesmo tempo que prepara a criança para que viva num meio de realidade fragmentada.

\section{Unidade/separação de si mesmo}

Enuncia unidade de si mesmo: o professor apresenta (ou não) preocupação com a consciência de si mesmo, como objeto passível de ser interpretado e desenvolvido na escola.

Enuncia separação de si mesmo: o professor apresenta (ou não) preocupação com a questão da construção do si mesmo apto para adequar-se ao meio que o cerca.

Enuncia tentativa de hábito de unidade na instituição: o professor apresenta (ou não) preocupação com a ligação entre os vários níveis da formação (emoções, cognição, expressão corporal, matrizes culturais e outros).

Enuncia práticas de equilíbrio unidade/separação: o professor apresenta (ou mista no sentido desta dualidade. 


\section{Conceitos complementares da unidade/separação de si mesmo}

Corporalidade: integração/não-integração do corpo e da gestualidade nos processos de formação/aprendizagem.

Enuncia corporalidade no plano físico: o professor enuncia, no discurso, a corporalidade na educação associando-a à Educação Física.

Enuncia o gesto social como fator de educação ethos-hexis: o professor apresenta (ou não) preocupação com a educação para a comunicação. O professor apresenta preocupação com um conjunto mais amplo de aquisições e competências que ultrapassa o domínio das disciplinas no primeiro ciclo. O professor apresenta pensamento e prática, nesta perspectiva.

É importante esclarecer que o termo gesto, aqui, assume sentido figurado. (Gesto [do fr. geste]: ação, ato - em geral, brilhante -; gesto de generosidade; gesto de nobreza ${ }^{9}$.)

Já o termo comunicação, aqui, evoca o sentido que possui na Escola de Palo Alto, ou seja, o sistema que designa a postura, a hierarquia e os movimentos concertados e integrados dos seus participantes e, também, os sentidos que possui quando designa os valores de distinção dos gestos sociais ${ }^{10}$ e a performance comunicativa qualitativa e dramática ${ }^{11}$. Dessa forma, o termo educação para a comunicação designa a educação que trabalharia com os sentidos relativos dos gestos sociais, os seus locais de origem socioculturais e a estrutura de um léxico correspondente no plano da gestualidade. Neste ponto, podemos nos perguntar sobre o porquê de a escola investir com mais ênfase em conteúdos associados à inscrição do que em conteúdos associados à incorporação, como sugere Connerton, para a esfera sociocultural em geral.

Enuncia interdependência entre corpo e formação: o professor apresenta (ou não) pensamento e prática relativos à questão.

Enuncia práticas de interpretação do si mesmo como corporalidade (significados sociais dos léxicos e modalidades gestuais em face do si mesmo): o professor apresenta (ou não) pensamento e prática relativos a uma hermenêutica do corpo (da gestualidade) ou do meu corpo em sociedade.

\section{Unidade/separação do outro}

Enuncia o conceito/hábito de atenção: o professor apresenta (ou não) preocupação em associar como unidade o si mesmo de cada um e o mundo, o outro.

Enuncia o conceito/hábito de seleção: o professor apresenta (ou não) preocupação com a organização seletiva dos conteúdos: disciplinas, separação de unidades curriculares. O professor faz distinção entre os conteúdos curriculares voltados para a informação cognitiva fundamental: Matemática, língua, estudo do meio.

Enuncia o conceito de mediação midiática: faz as representações do outro e do mundo chegarem até o indivíduo, além dos modelos que são passados pela família, comunidade e escola. Apresenta (ou não) os mídias na vida e os interpreta como narrativa do passado na perspectiva da expansão do presente, unidade do outro.
9. FERREIRA A. B. H. Novo Dicionário da Língua Portuguesa. 3. ed. Rio de Janeiro: Nova Fronteira, 1999. Ver também os conceitos de ethos e hexis, em BOURDIEU, Pierre. O poder simbólico. Rio de Janeiro: Difel, 1989. p. 171ss.

10. BOURDIEU, Pierre. O poder simbólico, op. cit.

11. GOFFMAN, Erving. A apresentação do eu na vida de todos os dias. Santa Maria da Feira: Relógio D’Água, 1993. 297p. 
comunicação \& educação • Ano X N Número 2 - maio/ago 2005

Enuncia práticas pedagógicas do equilíbrio atenção/seleção: o professor apresenta (ou não) preocupação em integrar os três itens anteriores.

\section{Conceitos complementares da unidade/separação do outro}

O PÚBLICO E O PRIVADO

Enuncia o conceito de público/privado: o professor apresenta (ou não) preocupação com a questão da formação voltada para a consciência pública do formando.

Enuncia o conceito de privado como problema: o professor apresenta (ou não) preocupação com as tendências de manifestação descontrolada do privado no ambiente escolar.

Enuncia práticas relativas ao problema: o professor apresenta (ou não) proposta de trabalho em relação à formação do sujeito público em face da cidadania e da vida privada.

Enuncia o equilbrio ou desequilibrio público/privado: o professor apresenta (ou não) o problema de forma a abordar os dois lados; a questão da unidade público/privado.

\section{PRÁtICAS MNEMÔNICAS NA ESCOLA}

Enuncia sistematização das práticas mnemônicas: o professor apresenta (ou não) pensamento e/ou práticas de separar e memorizar categorias cognitivas com a finalidade de permitir tarefas ativas (por exemplo: tabuada, seqüência de datas ou eventos distintivos e outras).

Enuncia o hábito de compreensão e a dispensa das práticas mnemônicas: o professor apresenta pensamento ou justificativa acerca da não-utilização das práticas mnemônicas na escola.

\section{UNIDADE/SEPARAÇÃO DA COMUNICAÇÃO}

Enuncia associação entre os fatores constituintes dos processos comunicativos: o professor apresenta (ou não) pensamento ou prática que associe a sociedade/meio, os mídias, a família, alunos e professores como elementos em comunicação.

Enuncia trabalho de formação do aluno para a consciência do sistema de comunicação: o professor apresenta (ou não) preocupação com pensamento e práticas de observar e interpretar sistemas de relação/interação - sistemas em jogo, interlocutores, gêneros de comunicação, realidades e possibilidades no plano da comunicação.

Enuncia a comunicação como espaço de aprendizagem global: o professor apresenta (ou não) preocupação com a unidade entre linguagem e comunicação linguagens de comunicação, inclusive a língua; modalidades de dizer no plano da comunicação não-lingüística.

Enuncia a noção de uso e potencialidade de usos, dos códigos, sistemas e hábitos de comunicação: o professor apresenta (ou não) preocupação com a capacidade 
de domínio de códigos, sistemas e hábitos - do seu meio e de outros meios por parte do educando.

\section{DIMENSÃO CONTINUIDADE/FRAGMENTAÇÃO}

\section{Continuidade/fragmentação do tempo}

Enuncia a consciência da incontornabilidade do tempo concreto: o professor dá (ou não) ênfase ao presente, síntese temporal do presente, no sentido de rever os gestos que se praticam como inércia do hábito contraído no passado.

Enuncia pensamento e/ou prática relativos à noção pulverizada do tempo: o professor apresenta (ou não) preocupação com a idéia de tempo utilitário e dividido.

Enuncia pensamento e/ou práticas com as noções de tempo contínuo: o professor apresenta (ou não) preocupação com a formação para o sentido de continuidade - a duração do passado e do futuro no presente.

Enuncia o presente como tempo de ligação entre o passado e futuro: o professor apresenta (ou não) pensamento e/ou práticas referentes à consciência de si, do outro e da comunicação como fatores de compreensão do tempo contínuo.

\section{Continuidade/fragmentação de si mesmo}

Enuncia práticas de narrativa do si mesmo: o professor realiza (ou não), com os formandos, práticas de narrativa autobiográfica e autocompreensiva.

Enuncia a noção de História como noção integrada à noção de si e do outro em processo contínuo e indivisível: o professor apresenta (ou não) preocupação com a capacitação do formando para a leitura de si como um desenrolar contínuo de relações complexas em um meio complexo, no tempo.

Enuncia a compreensão de si como contração e condensação de hábitos de si e do outro no tempo: o professor apresenta (ou não) a consciência de si como processo no tempo; o si em face do meio e do outro no passado.

Enuncia a consciência dos laços de passado e da herança do meio como fatores de interpretação de si: o professor apresenta (ou não) preocupação com a formação para a consciência de si, a classificação de si mesmo e a identificação do outro pelas narrativas sistemáticas e exercícios sobre o tempo passado.

Enuncia o trabalho com a noção de morte como fator de educação. Herança /legado como fatores de continuidade: o professor apresenta (ou não) preocupação com a questão da perda, do luto, da melancolia e do perdão.

\section{Continuidade/fragmentação do outro (do mundo)}

Enuncia a noção de história como fator de narratividade extensa do real: o professor apresenta (ou não) preocupação com a questão da representação do outro, no sentido da memória, da história, dos mídias e outros. 
Enuncia a noção de interpretação do vivido e a transformação do hábito no social: o professor apresenta (ou não) preocupação com a transmissão dos hábitos e a participação de alunos e professores neste processo.

Enuncia a narratividade e práticas éticas de pensar a História: o professor apresenta (ou não) preocupação com a questão dos silêncios e versões parciais sobre os conflitos humanos. A dinâmica do esquecimento e a sua gestão.

Enuncia práticas de integração entre a narrativa subjetiva e a histórica: o professor apresenta (ou não) pensamento e/ou práticas relativos à idéia de participação do sujeito no processo histórico. O professor faz (ou não) a distinção entre Memória e História. O professor faz (ou não) a relação entre as narrativas pessoais e cotidianas do mundo e do si mesmo e as narrativas históricas e científicas.

Enuncia práticas de interpretação e leitura que os mídias fazem do mundo: o professor apresenta (ou não) pensamento e práticas relativos à formação do educando para a capacidade de interpretar códigos e fenômenos utilizados pelos mídias.

Enuncia o equilíbrio entre práticas de continuidade e práticas de fragmentação: o professor apresenta (ou não) pensamento e/ou práticas voltadas para a ponderação de fatores de continuidade e a sua integração diante de um meio marcado pela fragmentação.

\section{Continuidade/fragmentação da comunicação}

Enuncia um continuum de comunicação com base no educando: o professor apresenta (ou não) pensamento/prática em relação à capacidade do educando em identificar de forma diacrônica o terreno de comunicação e as suas funções internas/papéis relativos no interior deste terreno (quem falava/fala; porque falava/fala; como falava/fala; com quem falava/fala; sistema no interior do qual se fala).

Enuncia práticas de identificação das redes de comunicação e de seus papéis: o professor apresenta (ou não) noções das redes de comunicação relacionadas aos papéis que acontecem no seu interior e relativas a todos os agentes: professores, familiares, comunidade e outros.

Enuncia a autonomia do sistema de comunicação em relação aos seus agentes: o professor apresenta (ou não) preocupação com a centralidade relativa do homem nos sistemas sociais e educacionais.

\section{DIMENSÃO SIMULTANEIDADE/LINEARIDADE}

\section{Simultaneidade/linearidade do tempo}

Enuncia a multiplicidade como fator de educação: o professor apresenta (ou não) pensamento e/ou práticas pedagógicas relativos à questão das possibilidades de revisão e escolha dos hábitos, bem como as várias perspectivas de análise de um mesmo objeto. 
Enuncia a linearidade como fator de educação: o professor apresenta (ou não) pensamento e/ou práticas pedagógicas relativos à ordenação linear do pensamento e do trabalho.

Enuncia a busca de equilíbrio entre a linearidade e a simultaneidade: o professor apresenta (ou não) pensamento e/ou práticas de construção de possíveis outros (modelos, formas, sistemas), ao mesmo tempo que pondera sobre suas utilidades e possibilidades.

Enuncia a consciência da velocidade cotidiana: o professor apresenta (ou não) pensamento e/ou práticas ante a questão da linearidade veloz.

Enuncia o estresse como resultado da velocidade: o professor apresenta (ou não) pensamento e/ou práticas relativos a situações de mau aproveitamento do educando devido ao estresse.

Enuncia a distinção entre o intervalo reflexivo e o intervalo para a retomada da ação: o professor apresenta (ou não) pensamento e/ou prática relativos ao intervalo tomado como descanso da ação disposta linearmente e o intervalo vivido como plano intuitivo da simultaneidade: o plano do refletir e do meditar; o repouso como tempo inútil em face da ação.

\section{Simultaneidade/linearidade de si mesmo}

Enuncia pensamento ou prática de análise de si mesmo na escola: o professor apresenta (ou não) promoção de análise e interpretação dos vários significados de si, conforme variação de referências. Promove revisão dos gestos de si mesmo como prática de mudança.

Enuncia gestos de si mesmo associados à linearidade: o professor apresenta (ou não) pensamento e/ou práticas relativos ao acompanhamento do educando no plano da manutenção e gestão das seqüências lineares da ação.

Enuncia aproximação dos planos simultaneidade/linearidade: o professor apresenta (ou não) pensamento e/ou práticas relativos à integração contraditória dos planos da simultaneidade e da linearidade.

\section{Simultaneidade/linearidade do outro}

Enuncia o outro possível: o professor apresenta (ou não) pensamento e/ ou práticas quanto ao exercício de imaginar um leque de possibilidades sobre qualquer tema/objeto permanente no cotidiano escolar. O professor propõe (ou não) abertura de atividade pedagógica para o exercício interpretativo dos tipos de outros existentes: sociedade, sistema escolar, sistema cultural.

Enuncia distinção entre as escolhas de agendas dos mídias e os temas proscritos/ silenciados: o professor apresenta (ou não) pensamento e/ou práticas relativos à interpretação crítica dos discursos e linguagens midiáticas: discurso sobre o outro e o mundo. 
comunicação \& educação • Ano X • Número 2 - maio/ago 2005

Enuncia a relação entre a velocidade cotidiana e a linearidade narrativa veloz dos mídias: o professor apresenta (ou não) pensamento e/ou práticas de associação entre o conteúdo dos mídias e os ritmos velozes do dia-a-dia.

Enuncia a integração dos objetos do conhecimento: o professor apresenta (ou não) pensamento e/ou práticas relativos à integração dos objetos: tempo, si mesmo, o outro e a comunicação.

\section{Simultaneidade/linearidade da comunicação}

Enuncia a comunicação como sistema escolhido/construído: o professor apresenta (ou não) pensamento e/ou práticas relativos à consciência da constituição dos sistemas de comunicação.

Enuncia a possibilidade de interpretação e mudança do sistema de comunicação: o professor apresenta (ou não) pensamento e/ou práticas que incentivem a mudança, no sentido de alteração sistêmica de Palo Alto.

Para finalizar, acrescenta-se que o instrumental de observação apresentado deve estar sempre aberto a todas as transformações que a investigação continuada do nosso objeto puder fundamentar. Por sua vez, as práticas memoriais na escola devem ser entendidas como fluxos complexos e alteráveis, e não dicotomias estáticas como à primeira vista se poderia supor.

Apesar de não ser objetivo deste texto enveredar pela experiência empírica desenvolvida durante nossa investigação, pensamos ser importante acrescentar que este instrumental de observação apresentado foi aplicado a três escolas do Ensino Básico das regiões de Oeiras e Lisboa e envolveu entrevistas extensas a 11 agentes discentes individuais (8 professores das $3^{\underline{a}}$ e $4^{\text {a }}$ Classes do Ensino Básico) e algumas equipes educativas (1 Diretor, 2 Conselhos Diretivos e um grupo de estagiários responsáveis pela Educação Física).

Cada uma dessas escolas corresponde a um conjunto de educandos pertencentes aos três grupos socioeconômicos presentes na perspectiva de Bourdieu (classes elevadas - Escola A, classes médias - Escola B e classes populares - Escola C). Obtivemos um resultado que pode ser sintetizado através da clara associação de estratégias pedagógicas ligadas à Duração na Escola A e à Abstração nas Escolas B e C. Nessa perspectiva, adiantamos que a explicação mais plausível para este fato reside na formação dos atores sociais adaptada às funções de reprodução social.

Dessa forma, supomos que nem uma Pedagogia da Duração nem uma $P e^{-}$ dagogia da Abstração podem superar o processo binário que está na base de tal reprodução. Sugerimos, assim, o amadurecimento de uma Pedagogia da Contradição constituída por estratégias educativas que, através de cenários construtivos e não-transferenciais, revelem aos educandos e educadores a dinâmica opositiva e complementar que permite a predominância de um tempo de abstração nos cotidianos educativos das sociedades contemporâneas. 
Resumo: O autor apresenta o modelo e os instrumentos de análise de um estudo realizado junto a escolas do Ensino Básico da região de Lisboa, que trata das questões da comunicação, da temporalidade e da memória cotidiana no âmbito da educação. Os pressupostos teóricos, de natureza interdisciplinar, fundamentaram-se nos trabalhos da Teoria Social da Memória. Com bases em autores como Henri Bergson, Paul Connerton, Edgar Morin, K. Pomiam, além de cientistas sociais e filósofos que pensaram a temporalidade e a memória social, o texto concebe duas tendências de viver a temporalidade no dia-a-dia: a primeira, voltada para a adaptação ao mundo, e a segunda, dirigida à compreensão/ construção do tempo vivido e a viver. As categorias identificadas pelo método e os indicadores qualitativos que as distinguem sugerem que os modos de memória não existem em forma pura, mas variam a partir de um jogo de interação entre a memórialembrança e a memória-hábito.

Palavras-chave: educação, comunicação, memória, tempo social, cotidiano.
Abstract: The author presents the model and the analysis tools of a research involving the issues of communication, temporality and daily memory in the field of education in elementary schools of the Lisbon region. The theoretical assumptions, of interdisciplinary nature, were built upon the works of the Social Theory of Memory. Based on authors as Henri Bergson, Paul Connerton, Edgar Morin, K. Pomiam, as well as on social scientists and philosophers who have thought the temporality and the social memory, this text conceives two tendencies of living the temporality in the daily life: the first one, turned to the adaptation to the world, the other one, directed to the comprehension/construction of the time lived and to be lived. The categories identified by the method and the qualitative indicator that distinguish them suggest that the modes of memory do not exist in pure manner, but vary according to a set of interactions between the memoryremembrance and the memory-habit.

Keywords: education, communication, memory, social time, quotidian, daily life. 